\title{
Integrated Health Care Systems and Indigenous Medicine: Reflections from the Sub-Sahara African Region
}

\author{
Beth Maina Ahlberg ${ }^{1,2 *}$ \\ ${ }^{1}$ Department of Women's and Children's Health, Uppsala University, Uppsala, Sweden, ${ }^{2}$ Skaraborg Institute for Research \\ and Development, Skövde, Sweden
}

Indigenous or traditional medicine has, since the 1970s, been widely regarded as a resource likely to contribute to strengthening the health care systems in low income countries. This paper examines the state of traditional medicine using evidence from three case studies in Central Kenya. While the cases are too few to represent the broad diversity of cultures and related healing systems in the Sub-Sahara African Region, the way they seem to refute the main assumptions in the integration discourse is important, also because studies from other countries in the region report perspectives, similar to the case studies in Kenya. It is often argued that people continue to use traditional medicine because it is affordable, available, and culturally familiar. Its integration into the health care system would therefore promote cultural familiarity. The case studies however point to

OPEN ACCESS

Edited by: Maria Clasina Stuttaford, Cardiff University, United Kingdom

Reviewed by:

Marion Heap,

University of Cape Town, South Africa Alexandra Plowright, University of Warwick, United Kingdom

*Correspondence: Beth Maina Ahlberg beth.maina.ahlberg@kbh.uu.se

Specialty section:

This article was submitted to Medical Sociology, a section of the journal Frontiers in Sociology

Received: 13 December 2016

Accepted: 25 August 2017 Published: 26 September 2017

Citation:

Ahlberg BM (2017) Integrated Health Care Systems and Indigenous Medicine: Reflections from the Sub-Sahara African Region.

Front. Sociol. 2:12.

doi: 10.3389/fsoc.2017.00012 the loss of essential cultural elements central to traditional medicine in this particular area while users travel long distances to reach the healers. In addition, there are significant paradigm differences that may present obstacles to integration of the two systems. More problematic however is that integration is, as in many development interventions, a topdown policy that is rarely based on contextual realities and conditions. Instead, integration is often defined and dominated by biomedical professionals and health planners who may be unfamiliar or even hostile to some aspects of traditional medicine. Furthermore, integration efforts have tended to embrace selected components mostly herbal medicine. This has led to isolating herbal medicine from spiritualism, which may in turn affect the holistic perspective of traditional medicine. While familiarity and relevance may explain the continued use of traditional medicine, its services may not be as readily available, accessible, or even affordable as is often asserted. Globalization set in motion through colonization and ensuing modernization processes, including urbanization, education, religion, and a neo-liberal economic system, have introduced a social order creating physical as well as social distances between users of traditional medicine and the healers.

Keywords: biomedicine, indigenous medicine, traditional medicine, herbal medicine, spiritualism, integration, cultural familiarity

\section{INTRODUCTION AND BACKGROUND}

Indigenous or traditional medicine has, since the 1970s, been widely regarded as a resource likely to facilitate reaching the goal of health for all, in low income countries. Several arguments are presented in favor of integration. First, it is argued that traditional medicine is readily available in many areas, is affordable, and serves over $80 \%$ of the population in low income countries (Kale, 1995; WHO, 2008, 2011). Second, traditional medicine continues to be popular even where western medicine is readily available (Ness, 1980; Homsky et al., 2004; Galabuzi et al., 2010). Finally, being part of the culture, it is 
argued that people readily accept it because it is familiar, although the three cases observed in Kenya indicate just how unfamiliar users can also be. Nonetheless, it is argued that the popularity of indigenous medicine could help meet the increasing demand for health care in low income countries.

In 1978, the Alma Ata Declaration recognized Traditional medicine and its practitioners as a resource for achieving health for all by the year 2000 (WHO, 1978; Chatora, 2003; Tilley, 2015). In 2000, the African Union (AU) Heads of State and Governments declared the period 2000-2010, the Decade of African Traditional Medicine (WHO, 2008). This meant, as noted by Appiah (2012), that African traditional medicine would be incorporated into the health care systems by increasing institutional capacity and developing national regulatory frameworks. In 2011, the AU decided to extend the Decade to 2020 (WHO, 2011). Meanwhile, WHO, declared 31st August of every year as the African Traditional Medicine Day (Chinsembu, 2009).

There has been progress following these policy declarations. The number of countries with national traditional medicine policies, for example, increased from 8 in 1999/2000 to 39 by 2010 and those with national traditional medicine strategic plans rose from 0 to 18. Country regulatory frameworks increased from 1 in $1999 / 2000$ to 28 by 2010. In May 2003, the Eastern and Southern African regions convened a consultative meeting for the Regional Initiative on Traditional Medicine and AIDS (Chinsembu, 2009). While great progress has been made and interest for integration is enormous, there seems also to be a lack of critical reflection on the changing state of traditional medicine.

The three cases that combined use of indigenous and biomedicine presented here were observed in Kenya. They illuminate why people still use traditional medicine, but they also indicate the nature of change taking place and the challenges posed to both users and healers. Many of the changes and related challenges are historical, and can be traced to the colonial interventions, when biomedicine, Christianity, urbanization, and western education were introduced (Good and Kimani, 1980). Traditional medicine and healers were ignored, outlawed, or criminalized as witchcraft and witchdoctors (Groves, 1948; Simmons, 2000; Ritcher, 2003). In addition, without insinuating that indigenous medicine was static, the social order that supported and regulated it was nonetheless disrupted (Ahlberg, 1991). While integration efforts may be conceptualized as an attempt to lift traditional medicine from the low status to which it was relegated, rarely are the changes that have taken place, considered in the integration plans. Critically examining the empirical evidence used by WHO and others over time, Rademeyer (2013) indeed questions the basis for the claim that $80 \%$ of the people in South Africa continue to use traditional medicine. In this way, what is going on in the integration discourse and practice could be assessed from a postcolonial perspective, defined here as a condition or process that has generated a kind of double-reality and consciousness with new and old formations at work all at once. In a similar way, Mbembe, (1992) defines postcoloniality as a state of multiple and overlapping directions simultaneously. This line of reasoning helps to reposition the dominant and the marginalized on the stage of cultural discourse to challenge representations of colonized and colonizing cultures in binary forms with essential unchanging features as seems to be in the integration discourse. This should allow reflection on the specific ways the African systems, such as traditional medicine, were and continue to be fragmented but also how they assume new forms. To gain an understanding of the changes taking place, a brief outline of the social foundations of both traditional and biomedicine is presented. Thereafter, three cases, two of which combined traditional medicine and hospital care and one which used hospital care only, will be presented to illuminate experiences of users and changes in traditional medicine. Thereafter, the paper presents experiences of actual integration in Nigeria, Tanzania, Ghana, and Kenya.

\section{THE SOCIAL FOUNDATIONS OF TRADITIONAL AND BIOMEDICINE}

Biomedicine is a product of western developments and is organized around the view that illness is as Coe (1970), p. 120, argues, a quantifiable episode and the patient is a case, subject to investigation and study by western scientific evidence. This is to say that diagnosis and treatment are based on scientific evidence. There is however an intriguing paradox in the state of biomedicine in the twenty-first century because, in spite of the level of scientific and technological developments and knowledge in biomedicine, diagnosis, and treatment are becoming increasingly challenged. The paradox is, at one and the same time, a product of societal advancements during the nineteenth and twentieth centuries. Then, the threat of infectious diseases was reduced through economic development, improved public health especially hygiene and the discovery and use of antibiotics and vaccines (Egger, 2012). However, by the mid-twentieth century, with economic development also came the epidemiological transition. Noncommunicable diseases or those diseases associated with lifestyle such as cardiovascular disease, cancers, hypertension, and diabetes with no single identifiable cause became the major threats to health. While these diseases are today the major cause of death globally (Yach et al., 2004), they are challenging. Besides being difficult to diagnose, they require long-term management, not just in medical institutions, but more significantly at the family and community levels (Yach et al., 2004; Kleinman and van der Geest, 2009). Home-based care has assumed a central position in caregiving, as has clearly become evident in the case of HIV and AIDS (Ogden et al., 2006).

Conversely, traditional medicine, in many parts of SubSaharan Africa, largely defines illness as a social experience believed to result from the breakdown of the social balance. This can be due to omissions or commissions, such as breaking codes of conduct now or in the past, ancestral spirits and also evil spirits. Ifeanyi (1992), p. 30, notes that in such a belief system, "health, involves not only physical exuberance but also harmonious integration of an individual with the entire universe, both spiritual and material." In this sense, traditional medicine is holistic in its approach. The healer treats the disease as well as its root cause, which more often than not are associated social relationships. The ultimate goal as argued by Mokaila (2001) is to restore the individual to a harmonious relationship within the social environment. The need to identify disturbances 
in the social environment outside the individual as cause of illness makes the interaction between the patient and the healer intimately intensive (Labhardt et al., 2010).

The Gikuyu people of Central Kenya where the three cases were observed, had a social system prior to colonization, where social balance and the well-being of the individual, clan, lineage, and the entire community was strongly linked to the conduct of individuals and groups in the society (Kenyatta, 1938; Dodge, 1964; Kinoti, 1983; Mugambi, 1989; Ahlberg, 1991). This social system was furthermore organized around the belief in ancestral spirits and other supernatural deities that could punish the living for misconduct or for not rectifying omissions and commissions of family members presently or in the past. Certain individuals described as having an evil eye could also create imbalance in individuals and families. Misfortune and suffering could be experienced by persons or groups other than the one breaching the code of conduct. To maintain social balance and avoid the wrath and punishment by the ancestral spirits and other supernatural deities, living according to what was defined as proper conduct was of utmost importance in the daily lives of the people.

To ensure that individuals and groups maintained good conduct, the Gikuyu society was organized in ways which minimized misconduct (Ahlberg, 1991). Taboos which touched on many aspects of life were extensively used to guide conduct. In addition, ritual ceremonies were performed and sacrifices offered, not just to rectify a breach of conduct but perhaps more importantly, to prevent its occurrence. Social pressure was similarly exerted through peer groups and networks to enforce socially accepted conduct thus preventing occurrence of illness and other misfortunes. Within such a social system where illness could be collectively experienced, curative and preventive actions were collective. Other societies such as the Nyakyusa in Tanzania (Wilson, 1957), the Akan in Ghana (Appiah-Kubi, 1981), the Kaguru in Tanzania (Beidelman, 1982), the Yoruba in Nigeria (Taye, 2009), the Luo in western Kenya (Hauge, 1974), and the Kamba in eastern Kenya (Ahlberg, 1979) had similar belief systems and healing practices. In addition, Mbiti (1969), Gaba (1997), Zahan (1979), Ray (1976), and Ifeanyi (1992) make similar observations about African societies in general.

However, even for African traditional medicine, illness was and is even today also attributed to causes other than social disharmony, breach of conduct, ancestral, and other evil spirits. A disease such as measles, which occurs in epidemics, is shortlived and confers lasting immunity upon a child when it occurs, the basic question "why my child" may be less applicable. This is because many children in a neighborhood are likely to be affected at the same time. Moreover, the course of action for such a disease may be well known. When measles is suspected, the Kamba people for example, do what is culturally believed to be appropriate to hasten the eruption of the rash (Ahlberg, 1979). This confirms in part that the disease is measles, and it is taking the expected course. However, while the question "why my child" may be irrelevant for a family, people may still worry why an epidemic appears when it does. Some ritual ceremony may thus be necessary to determine the likely cause and to restore balance.
The second category includes those diseases with irregular pattern of occurrence. A fracture is, for example, physiologically well understood by an traditional bonesetter (Appiah-Kubi, 1981). Yet, because of its rather unclear pattern of occurrence, it is a condition which strongly raises the question "why me?" Thus, even though the bonesetter may effectively manage a fracture, divination is considered necessary to remove the cause or prevent recurrence.

The effectiveness of a healer in diagnosing and prescribing the course of treatment does not therefore depend on her/his supernatural powers alone. Most important is perhaps how conversant the patient and kins are; about their family background, major family events several generations back, social values, beliefs, and rules of conduct. This category of traditional healers thus prevail in a wide range of societal ritual ceremonies necessary to ensure maintenance of harmony and social balance or what may be called preventive medicine.

From a sociological perspective, traditional medicine was, like other social institutions, well integrated into the social order. Disruption of any part of the social order, as has been the case with globalization and modernization processes since the onset of the colonial assault have had reaching consequences as discussed by Ritcher (2003) about traditional medicine and traditional healers in South Africa. Traditional medicine was categorized as witchcraft and the healers especially diviners as witchdoctors. This implies that divination and other rituals were given a name. Moreover, traditional medicine was criminalized and was consequently stigmatized, which may have forced it underground. The phenomenon of witchcraft and the forms it has assumed today, including witch hunting, ritual murders, and commoditization of body parts, is perhaps part of the transformation of traditional medicine which can be explained as response to the assault and disruption.

The changes arising from the assault do not however imply that the traditional medical system was static. It was, like other social systems, dynamic. However, with the assault and imposition of western systems, today's manifestation of witchcraft could be understood as a form of resistance. According to Stenberg (2010), divining or what the colonialists named witchcraft had traditionally played the role of maintaining harmony. Within the changing social landscape where deep inequalities or social differentiations have emerged, it is now used to explain who could be behind the misfortunes, but also to protect the wealthy people from being bewitched by jealous neighbors. Federici (2010) argues that the neo-liberal economic policies of the 1980s and 1990s in particular stripped entire populations of their means of subsistence, tore communities apart, and deepened economic inequalities forcing people to compete for diminishing resources. According to a UNICEF study (2010), "the coming of capitalism and creation of wealth among a limited group has led to increased jealousy and envy." Mildnevora (2016) similarly argues that while the discourse surrounding witchcraft in Zambia integrates both modern and traditional elements, it also reflects on the deprivation of ordinary people as a result of economic marginalization. These developments can explain the current witch-hunts and persecution of those considered to be witches, which according 
to the UNICEF study (2010) is prevalent in all countries in Sub-Saharan Africa. Simmons (2000) concludes by noting the paradox where forces that constitute what is labeled "modernity" are the same forces feeding to the proliferation of witchcraft. This to Simmons means that "witchcraft is part of a deeply historical form of sense making which has adapted to the exigencies of modern African life." This point is further articulated by Moore and Sanders (2001) that contemporary witchcraft is not a return to backwardness. Rather, it is the "modern manifestations of uncertainties, moral disquiet and unequal rewards and aspirations in the contemporary moment." Ritcher (2003) moreover notes how, the colonial suppression of witchcraft and the encroachment of western medicine in South Africa blurred the roles of diviners and herbalists. According to Mildnevora (2016), the 1995 Witchcraft Act in Zambia, forbid witch-finding activities and the constitution of the Traditional Health Practitioner's Association of Zambia adheres to the same Witchcraft Act. In spite of this, there are according to Mildnevora (2016), many witch-finders round the country working as herbalists, diviners, and spiritual healers, without advertising themselves publicly as witch-finders, but doing a lucrative business of witch-finding for a large number of both marginalized, but also wealthy people.

Another development that seems to be shaping witchcraft is the growing phenomenon of charismatic Pentecostal Churches. These churches have capitalized on preaching against witchcraft and exorcizing the evil spirits. This has become the major tenet for pastors in these Churches. According to Foxcroft (2014), the rise of Pentecostalism has led to increased witchcraft accusations especially against women and children who are held responsible for dark events in communities and is considered as justification for violence against those identified as witches. Unlike the early Christian Missionaries who condemned traditional medicine as witchcraft, the Pentecostal Churches today both condemn witchcraft and exorcize the evil spirits from those believed to be witches in their congregations. In a study by UNICEF (2010), children accused of being witches may be killed, while others may be abandoned by their parents. Given these developments, there is need for more critical reflection in the integration discourse regarding what is integrated, what is left out, but more significantly what may happen when fragments are taken from the whole.

A number of questions may need to be asked at this point. Is there, for example, knowledge regarding the number of traditional healers, their specialization, and their reproduction or the nature of change taking place in their practice? Does the focus on only selected aspects of traditional medicine in the integration isolate parts of a whole system? Have colonial laws which criminalized traditional medicine as witchcraft been well reflected on and how? What do these questions imply for integration of traditional medicine into the health care systems, for the users of traditional medicine and the healers? Some of these questions are reflected in the cases discussed below. The cases illuminate some of the challenges both users and healers of traditional medicine encounter. These cases were observed during a study entitled: "Prevention of HIV/AIDS among youth in Kenya through understanding sexuality and reproduction." The study was based at the Department of Community Health, Nairobi University and was carried out between 1992 and 1996.

\section{METHODS}

One objective of the HIV/AIDS study was among others to explore the different sources of healing used by the people, and the meanings they attached to seeking health care from these sources. This involved using a variety of methods including interviews, observations, participatory workshops with different stakeholders, and written narratives by school youth. Furthermore, because of the silence on issues of sexuality, expressive methods such as local proverbs, role plays, relevant videos, and past cultural practices were used in part to make an invisible problem visible and facilitate discussion and reflection the traditional healers were visited to explore how they engaged with HIV/AIDS. It was during these visits that the patients who consulted traditional healers were interviewed.

\section{THE SETTING AND DATA COLLECTION}

The study took place in Muranga County, Central Kenya. The two patients came when the researcher and author of this paper was interviewing the healers. In total, five healers were visited during the study, but only two received patients when the researcher was interviewing the healers on how they engage with HIV/AIDS. None of them were visited by patients with AIDS during this time. In one case, the researcher was asked by the healer to wait until the patients were treated, and the interview was conducted after treatment. In the other case, the researcher was allowed to be present in the healing session. The patient who consulted hospital care only was a participant in a community group, discussing how parents communicated with their teenage children on issues of sexuality. She was visited and interviewed at her home because she mentioned she had not been feeling well for sometime. In an informal conversation, she was asked whether she had visited a traditional healer. She emphatically replied that as devout or "born again" Christian, traditional medicine was not a choice for her. She was then encouraged to narrate what she had done in the course of her illness.

The two patients who consulted traditional healers were urban-based. They had used health care facilities but explained they had not been cured. Indeed, it was explained that the mental health patient had been given medicines for treating madness. For this reason, the family will never use the hospital care again. These two urban-based patients had therefore traveled to the rural area to consult healers unknown to them, although according to the integration discourse, patients have access to healers who live among them. In the case of the mental health patient, the healer could only diagnose. For treatment, the patient had to travel some $500 \mathrm{~km}$ to a healer from another ethnic group. The healers from this area were, according to this particular healer, too young to treat the illness the patient suffered from. In addition, the healer became frustrated because there was little knowledge of the social and cultural environment of the patient which is central for proper diagnosis and treatment. In the other case, the healer could diagnose and treat the patient. However, treatment 
could not start immediately, and when started, the patient had to remain in the healer's compound for 1 week.

\section{ETHICAL ISSUES}

The main research had been given ethical clearance by the Office of the President: Provincial Administration and Internal Security: permit number OP/13/001/14C 77/16, on 7th January 1992. The permit was extended from February 1995 to 31st December 1996. All participants including the three patients in this paper were informed about the research and were informed that they would be interviewed only after they gave consent. All the healers visited during the study too were asked for consent. The participants were informed they were free to opt out even in the middle of the interview should they change their mind. They were assured they would remain anonymous and fictitious names are used in this text as a safeguard.

\section{CASE 1: CONSULTATION OF A HERBALIST/DIVINER FOR MEDICAL AND SOCIAL PROBLEMS}

Nyakio is a middle aged, unmarried mother of four. She lives in a slum area of the capital city Nairobi. Except for one daughter who is married, the other three children live with her in a single room. One of the younger daughters is an unmarried mother too. She performed poorly in her exams. Nyakio is worried that her youngest daughter, currently in school will fall into the same misfortune. Her only son ran away from school to join the city's street children commonly known as "parking" boys. Now and then he is picked up by police. The oldest daughter is married to an educated and wealthy man, but she had a baby girl before her current marriage.

Nyakio has had general aches all over her body for some time. She has been to a health center in the city, but she was not cured. Her eldest daughter has abdominal pains. They decide to consult a traditional healer. They both wish to have their health problems diagnosed, the cause established and be treated. Apart from these health problems, the two women have problems of a social nature. They therefore need a healer who can manage the two problems simultaneously. Nyakio would like to find out the cause of problems facing her children. She especially wants a healer who can treat and make her son a responsible person and protect her youngest daughter from getting pregnant before completing her education. Her eldest daughter is similarly looking for a medicine or charm that would prevent her husband from loving and spending his money on other women and continue to love his step daughter. The visit to the healer is organized to deal with these health and social problems. On arrival, they wait for their turn as the healer has a patient and besides, treatment cannot start before he consults his supernatural powers.

When their turn comes, they get into the healers' room. After a short conversation, the daughter is asked to wait outside. Before she leaves the room, the healer looks up at the younger woman and remarks:
I have read your face. I can already tell what is bothering you.

This remark assures the two women that the healer would indeed solve their problems. Nyakio and the healer discuss for over $1 \mathrm{~h}$ after which the daughter is invited in. At the end of the diagnosis, they both can go home. But when treatment starts, they must remain in the compound for 7 days to avoid breaking the rules necessary to make the treatment effective. This is problematic for the younger woman. How can she explain her absence from her family for seven days without raising suspicion? They go home figuring out how they can get around the problem.

\section{CASE 2: CONSULTATION OF A DIVINER ON BEHALF OF A MENTAL HEALTH PATIENT}

Muthoni's husband acts as though he is mentally disturbed. He is a policeman but he refuses to go to his job. He fears everybody and has traveled from the city to his rural home. It is impossible to get him into a car and most of the time he locks himself in the house.

Muthoni has traveled from the city to the rural home, over $100 \mathrm{~km}$ to consult a healer, the third she has consulted for this problem. She has also been to a hospital where her husband was given medicine for treating madness. Although she is concerned that he should recover, Muthoni, who is accompanied by a young male relative, will not take her husband to hospital again.

The healer begins with a prayer. He spreads an old sack under a mango tree and places a calabash and a small fly whisk. He then shakes the calabash and draws out pebbles, examines them, counts them, then looks at Muthoni, and asks questions to establish who she is and what she has for social relationships. Is there, for example, a clan with which her clan or that of her husband should not intermarry or interact in any other way. To his surprise, Muthoni knows little about their clans. The healer then addresses other areas. Shaking the calabash and drawing pebbles, he calls out a few names, and asks whether any of her husbands' relatives are known by that name and who they are. This does not take the healer very far either. He then asks Muthoni:

Can you tell me about the sickness that has brought you to me?

Rather surprised, Muthoni asks whether the healer cannot see the sickness in her husband. The healer replies there is sickness alright, but that he would like to know more about it from Muthoni herself. Muthoni then describes her husband's problem.

The diagnosis starts all over again. The healer tries to establish what could have caused the imbalance in Muthoni's family. An attempt to link the sickness to the clans fails once again. The healer gets surprised that Muthoni has not bothered to learn such basic concepts in illness and treatment in this area.

He then tries to find out whether Muthoni's husband could have quarreled with anybody in the village which Muthoni affirms. She describes an incident where her husband had, together with 
other men, beaten up a man in the village for allegedly not being circumcised. The healer wonders how they could have known this but turns his attention to information about the clan and the family background of the allegedly uncircumcised man, as well as her husband's involvement in the fight.

The healer draws more pebbles from the calabash to establish whether this was the cause of the illness. After a span of $10 \mathrm{~min}$, drawing pebbles and studying them carefully, the healer announces that the fight is the cause of the problem. Looking unconvinced, Muthoni continues to tell the healer that the victim of the fight was incapable of harming her husband to that extent. The healer shakes the calabash again, draws more pebbles out and looks at them again. He asks why she thinks so, while he sees the man to be an evil one:

The powers show me that the man is bad and the poison he has used on your husband is not our type. It is a poison used by people in the western part of Kenya. It actually looks like the one used by the Boran people.

The healer then asks whether there are such people near Muthoni's family. Still looking unconvinced, Muthoni asks the healer to check whether there is any connection with a woman, and also whether the problem could have originated from the job environment. Muthoni notices that the healer has mentioned a woman's name several times, and she wants to know more about that name. The healer starts all over again. He sets smaller pebbles around three large pebbles which he says helps him to see the job environment. He then examines them closely, each time shifting them around. Meanwhile Muthoni continues to explain about the name Wambui, which has featured prominently during their interaction.

Wambui is a colleague of her husband working at the same station and holding a similar position as her husband. They are neighbors in their residential area and other healers have found her to be the cause of the problem. The healer shifts his attention to Wambui. Examining the pebbles still set in small heaps on the sack, he sees Wambui to be an evil woman. He can even see that Muthoni's husband is not the first person Wambui has made ill. Muthoni confirms that Wambui even killed her former husband through a road accident and she also associates with the Boran and such other people, whose poison the healer suggested was used on her husband.

After establishing the cause of illness, Muthoni has to go to another healer, but this healer says he would help her identify the most effective one. He is quiet for a moment figuring out whether there is a healer in the neighborhood who can deal with the poison used on Muthoni's husband. The only healer, who could, died a year ago. The others are young and cannot deal with poisons from other areas of the country. Examining the pebbles for a moment, he recalls a Luo healer he met in the city many years ago but he has heard that this Luo healer left the city. Muthoni knows that he lives in Kisumu, some $500 \mathrm{~km}$ west of Nairobi. They therefore check whether indeed he is an effective healer. More pebbles are drawn from the calabash. Five pebbles come out. He draws again and again. To his amazement, five pebbles come out each time. He almost screams with joy:
The pebbles show me the Luo healer is an extremely effective one!

Muthoni should go to him without hesitation. They should however be prepared to pay heavily for his services and when they travel, they should avoid meeting wild animals because this would result in the death of the patient. She wonders how they can avoid this, particularly if they travel by public means. He has no answer, but he insists they should avoid this happening.

\section{CASE 3: THE HOSPITAL SURGICAL PATIENT}

Esther, a staunch Christian has been sick for some time. She has visited her local health center in her rural home several times. Each time she is given tablets and told to return if she is not cured. She decides to travel the $100 \mathrm{~km}$ to the National Hospital in the capital city. She is a widow and is accompanied by her son who works as a civil servant in a government office.

Accessing treatment at the national hospital is not easy either. She has to wait in a long filtering process. Toward the end of the day, she comes to the first doctor who asks what her problem is, in a language she hardly understands. Her son explains things on her behalf. She is then asked to line up at another door. After some search, they join the queue. Eventually she comes to another doctor and after a short explanation of her problem she is asked to lie on a small bed. The doctor quickly examines her, prescribes some medicines, and tells her to return if the pain persists. It is time to queue for the medicine and when her turn comes, the medicine is thrown at her with little explanation.

She goes home, takes the medicine but the pains persist for which she travels again to the city. Accompanied by her son, she lines up and is filtered to the appropriate section. The process takes another full day and at the end she is sent to the X-ray section where she is asked to undress, put on a coat and stand against a machine. She is asked to return after a week for the results. She goes home convinced that the huge machine would show what has troubled her for so long.

On the appointment day, Esther is lucky because she only waits among the X-ray patients and those others waiting for results from other tests. She waits wondering whether the big machine found her disease and what disease it is and would they now cure her? It is thus a big disappointment when the doctor tells her that the machine did not find any disease. She wonders where the disease could be hiding. She is asked to provide urine and stool for more tests, but she wonders, if the big machine could not find the disease, how can urine and stool tests manage. She goes home most disappointed. Luckily, women neighbors tell her of a mission hospital, within the suburbs of the city with better treatment.

Esther makes arrangements to travel to the mission hospital to start all over again. Because mission hospitals are expensive and her money is not enough, she must get additional funds from her son who also has to accompany her to the hospital. At the mission hospital, stool, urine, blood, and X-ray tests are immediately taken and as before, she has to travel several times for her results. Eventually, her disease is diagnosed as gall stones which require 
an operation. Esther wonders whether there is no other way to treat her disease. She knows many who have died after operation, but she decides to go through it, reasoning that if she dies, it is only the will of God.

The operation is not easy because, if carried out at the mission hospital, she would have to pay US\$ 500. In no way can she afford such an amount. The doctor offers to operate her in his private clinic for US\$300, but this is not a viable or realistic solution either. Other alternatives are her district hospital or the national hospital. She chooses the national hospital but as she is not referred from a public facility, it is very difficult to be admitted there, where the operation is otherwise free.

The doctor at the mission hospital nevertheless gives her a letter to take to the national hospital. In the days that follow, all the resources of Esther and her son are used finding ways of getting her into the national hospital. On arrival, the doctors demand to know "who the hell referred her" to that ward. She thus considers leaving without treatment. A woman patient from the city, however, whispers and advises her against leaving even if it means standing there for a whole week. After waiting without food, water, or somewhere to sit, a bed is found by the end of the day. Her operation is carried out the following morning and she does not die. In her words "this was not my day to die."

These three cases illuminate the experiences of the users including, how they concretely integrate or not integrate the two systems. They also illuminate the challenges faced, particularly by those who chose traditional healers because of not having the cultural competence necessary for proper diagnosis and treatment. In order to clarify what this lack of cultural competence implies for the integration discourse and the actual attempts to integrate the two systems, a few examples of integration are briefly reviewed.

The case studies are from one country and cannot be expected to represent the diversity of cultures and related traditional healing systems. However, given the assumptions in the integration discourse that people in low income countries continue to use traditional medicine because it is affordable, easily available, and culturally familiar, the cases refute these assumptions. The patients chose the traditional healers, even though they were expensive because they fulfilled their health needs as they perceived them. As indicated earlier, similar observations have been made in Cameroon (Labhardt et al., 2010) and South Africa (Ritcher, 2003) where patients pay more to get what they want from traditional healers. Clearly more elaborate research on use of traditional medicine is needed in order to get a deeper understanding of changes taking place in traditional medicine including the rising costs. The short review of specific integration efforts in different countries in Africa indicates that the main interest in the official integration is the herbal medicine.

\section{A SHORT REVIEW OF INTEGRATION EFFORTS}

In the context of poor health care as illuminated by the case of the hospital surgery patient, the call for integration of the two systems is clearly necessary. However, a closer look at the specific attempts for integration suggests that integration is not meant to unleash capacities of the two systems to improve the provision of health care. These integration efforts do not in other words, systematically blend the practices, technologies, and practitioners of the two systems in ways that enrich them for better provision of health care as argued by Taye (2009). Instead, it is the biomedical professionals who according to Wreford (2005) train the traditional healers with little reflection on how processes of change have and continue to affect the traditional medical system. This point was similarly made by Hoff (1992) in his review of 17 projects around the world where integration efforts had been made. Among constraints observed by Hoff (1992) was the absence of clear recognition by governments regarding the potential value and role of traditional practitioners. This lack of recognition was observed to create a poor working climate between traditional healers and biomedical professional which tends to reinforce secretive practices among the traditional healers with Nigeria mentioned as a case. Because the role of healers was not well defined in Nigeria, some healers feared their integration into the primary health care program might threaten their status, income, and freedom in their communities. He further noted that in countries where healers had been prohibited from practicing, many were reluctant to participate in health programs sponsored by the government. This implies that the biomedical professionals and government health policy makers and planners do not properly consult or engage the healers in ways that help gain knowledge concerning the state of traditional medicine (Abdullahi, 2011). Integration in four countries including: Nigeria, Tanzania, Ghana and Kenya indicate that collaboration is mainly limited to herbalists, leaving out the spiritually inspired healers.

In Nigeria, the National Medical Association recommended recognition of traditional medicine to the government, but objected, at the same time, the recognition of what was referred to as witches, sorcerers, extortionists, and soothsayers (Last and Chavunduka, 1986). The Association moreover warned that herbs and drugs administered by traditional healers should be subjected to rigorous scientific analysis to identify their specific medicinal potential and potency (Oyebola, 1980). Rigorous scientific analysis of herbs to ascertain their quality, safety, and efficacy is the common goal in many policy declarations on integration (WHO, 2011).

In Tanzania according to the Muhibili University of Health and Allied Sciences (MUHAS) (2016), the Traditional Medicine Research Unit, now known as the Institute of Traditional Medicine was established by an Act of Parliament in 1991. The mission as stated was "to carry out research on traditional medicines and promote the development of standardized herbal and plant derived pharmaceuticals as well as useful non-material aspects of traditional medicine through teaching and consultancy for the improvement of the health of the Tanzanian people." Although there is mention of researching on beneficial customs and practices of traditional medicine, most emphasis is put on promoting commercial exploitation and conservation of medicinal plants that could contribute to discovery of new drugs. Emphasis has therefore been on clinical trials and chemical analysis of local medicines. However, with the growing phenomenon of commoditization of body parts especially those of people with 
albinism, witch hunting and killing, the Tanzanian government has been forced to ban, detain, and prosecute the witchdoctors (Masanja, 2015). But given as described by Mildnevora (2016) the way witch-finding activities are secretive and that herbalists may also be involved, how to identify who should be detained and prosecuted seems a daunting mission and it seems no wonder as reported by Hoff (1992) the healers do not trust the governments.

In Ghana, integration has according to Appiah (2012), similarly been limited to traditional herbalists, leaving out spiritualism, psychic healing, soothsaying, and fortune telling or those aspects which, according to those responsible for integration, cannot be scientifically proved. The Department of Herbal Medicine at Kwame Nkrumah University of Science and Technology in Ghana has since 2001 trained 112 herbalists, 30 of whom have been placed to work in public hospitals (Appiah, 2012). Furthermore, the Ministry of Health has designated 18 public hospitals for integration of some of the herbal components of African traditional medicine into their daily practice. Perhaps most important in this collaboration is the identification of a large number of herbs and herbal medicine and the disease conditions for which they are used. The government has in addition approved a list of 86 herbal remedies. The head of the herbal medicine unit in one hospital reports the progress made in this integration in the following way:

We even have internal referral systems so that when physicians identify patients who need alternative forms of treatment for diseases such as hypertension and diabetes, they refer them to us .... we also refer cases that need orthodox treatments to physicians.

This referral system has revealed that most herbal medicines are not popular among patients. This is because the medicines are in liquid form which is considered inconvenient not to mention the concerns over the quality of water used in their preparation. This observation has resulted in plans to support and build pharmaceutical infrastructure to enable preparation of herbal medicine in convenient dosage forms such as tablets and capsules. It is also noted that creating such infrastructure will potentially provide possibility for observational studies on the efficacy and safety of the herbal medicines. Leaving out the spiritualism, psychic healing, soothsaying, and fortune telling aspects of traditional medicine on the grounds that they cannot be scientifically proved however constitutes a major oversight. How will these aspects which are part of the holistic treatment and care be scientifically proved or observed if at the same time, they continue to be ignored?

In Kenya as elsewhere, the Kenya government recognizes the importance of traditional medicine. In the financial year 2011/2012, the Traditional Medicine and Drug Development Programme was established within the Kenya Medical Research Institute. The purpose was to identify and develop effective traditional/alternative medicines and drugs for use against human diseases in partnership with relevant institutions and Government ministries. In addition, the program would provide information on quality of selected drugs in the Kenyan market. It is expected that this will lead to increased documentation of medicinal plants and traditional medicines and promote use of safe and effective traditional medicine. Most of the research as argued by Kigen et al. (2013) focuses, as in other countries, on screening for ingredients from plant extracts for pharmaceutical reasons.

These observations suggest that most efforts have primarily focused on the training of herbalists and use of laboratory research to validate medicinal potency of herbs (Akerele, 1993). Indeed, herbalists are indigenous practitioners whose healing roles are similar to drug prescription in biomedicine and are therefore better understood by biomedical professionals and health planners. Moreover, herbal medicine has, as Kofi-Tsekpo (2004) argues, also become a catchword. The use of herbal remedies or what is now called alternative medicine has gained popularity globally and has become a lucrative global industry which also seems to reflect the paradox in biomedicine mentioned earlier (Yach et al., 2004). This increased need for alternative medicine has led to patenting of traditional medicines, without consent from or compensation to the knowledge holders as reported by Timmermans (2003). But even where healers may be consulted or included in the patenting, because of the nature of traditional medicine, where knowledge has been passed from generation to generation of healers orally, who as questioned by Kavelin (2008), can be said to have discovered the medicine? This notwithstanding, the selective integration of traditional medicine in fragments or without acknowledging and understanding how what is being integrated has changed is a critical oversight. The integration does not only continue to dismantle the cultural heritage but also the holistic nature of traditional medicine which as observed in case one and two creates challenges for users and healers. A situation seem to have been created where what goes as traditional healing may be left to the healers, who often are then accused of being "quacks" or witchdoctors. Moreover, the socioeconomic structural changes in the region have created increased need among the marginalized people for explanation of their vulnerable position and the rich few for protection from jealous neighbors.

\section{DISCUSSION AND CONCLUSION}

This paper argues that people continue to integrate traditional and biomedicine to meet their health needs as they perceive them. Cases one and two illuminate how the users concretely navigate and integrate the two systems in Kenya. Traditional and biomedicine may be used one after the other, not only because of perceived failure to cure, but also because each system fulfils distinct needs for the users that can only be accessed there (Kale, 1995). Traditional healers are often consulted because they deal with health, social and psychological problems simultaneously.

The two patients (Nyakio and her daughter) who used traditional herbalist/diviner expressed the need for a holistic approach for their health and social problems. Beside the subjective pain they said they experienced, they had social and family problems which needed to be dealt with and future problems prevented.

Nevertheless, the continued use of traditional medicine is not without problems. Contrary to the integration discourse, traditional medicine is indeed neither easily accessible to the users, nor affordable. The users of traditional medicine may travel long distances to healers unknown to them for reasons similar to 
those that led to the by-passing of rural medical facilities by the hospital surgical patient. The case of the mental health patient suggests that healers who are perceived as competent are in short supply in some areas, which means patients may have to travel long distances. In their study in Cameroon, Labhardt et al. (2010) similarly observed that patients bypassed western facilities and traveled long distances to get to the traditional healers even though consultation and treatments were also much more expensive.

Furthermore, the internal structure where diagnosis may be separate from treatment has implications to accessibility and cost of traditional medicine (Non-hlanhla et al., 2011). Even where a healer combines diagnosis and treatment, the entire process may, as indicated in case one in this study, take a couple of days, even weeks. In the situation where the patient may be consulting a traditional healer secretly as was in the case with Nyakio's daughter, the time factor becomes critical. In some cases, a healer may only diagnose and refer the patient to another healer for treatment as was the case with the mental health patient. This means that like in hospitals where patients may be referred to other specialists or are asked to return for further treatment or for tests, users of traditional medicine similarly make a number of visits for one disease episode. In addition, given that at least one family member accompanies the patient, both transport and treatment costs in traditional medicine could be as exorbitant as the mission private hospital observed in this study.

Although users integrate the two systems, they have at the same time lost some of those cultural elements that make traditional medicine effective. The family of the mental health patient had for example, little knowledge or idea about the value of the clans, the kinship system or family events, which are central in diagnosis and treatment in traditional medicine. Without cultural competence among users, survival of traditional medicine may be threatened. But while users may lack the necessary cultural competence, there are in addition, groups who, based on religious grounds, are negative to traditional medicine. The extent of such groups or their attitudes is similarly not well known. Such negative attitudes can be critical particularly now when Charismatic Pentecostalism and faith healing movements are sweeping across Africa. Among others, these charismatic Christian movements chastise witchcraft (Ukpabio, 2011). Perhaps more serious today is the official call for integration with no reflection on the changing nature of traditional medicine. As mentioned earlier, the extreme forms in which witchcraft has unfolded including

\section{REFERENCES}

Abdullahi, A. A. (2011). Trends and challenges of traditional medicine in Africa. Afr. J. Tradit. Complement. Altern. Med. 8, 115-123. doi:10.4314/ajtcam. v8i5S.5

Ahlberg, B. M. (1979). Beliefs and practices concerning treatment of measles and acute diarrhea among the Akamba. Trop. Geogr. Med. J. 31, 139-148.

Ahlberg, B. M. (1991). Women, Sexuality and the Changing Social Order: The Impact of Government Policies on Reproductive Behaviour in Kenya. New York: Gordon and Breach Publishers.

Akerele, O. (1993). Nature's medicinal bounty: don't throw it away. World Health Forum 14, 390-395.

Appiah, B. (2012). African traditional medicine struggles to find its place within health care. CMAJ 184, 16. doi:10.1503/cmaj.109-4277 witch accusations and hunting can be understood as resistance to such exclusion within the integration discourse and practice. It is not clear what it means to collaborate with herbalists who may also be diviners and at the same time deliberately leave out spiritual healers or spiritualism, the aspect of healing for which the users in this study or those observed in Cameroon (Labhardt et al., 2010) or in South Africa (Ritcher, 2003) used the healers for. Since as observed above, there seem to be connection between structural changes and escalation of witchcraft and witch hunting activities in many parts of Sub-Sahara African region (Simmons, 2000; Stenberg, 2010; UNICEF, 2010; Mildnevora, 2016), there is clearly need to critically reflect on the vulnerabilities arising from these structural changes as part of the integration of traditional medicine.

If the goal of integration is not just to utilize traditional medical practitioners as extension workers to help in expanding coverage of health services, but rather to promote those unique elements of both systems of health care and blend them to improve quality of services, then there is need for new directions. Those elements of traditional medicine less understood or ignored by biomedical professionals will need to be understood through research, education and training. There is need, to include the teaching of the foundational principles of traditional medicine not just in medical schools as is often suggested, but in all schools starting at the primary level in part to understand the impact of structural changes. In such a process, the indigenous healers themselves could be actively involved, because it is them who have the knowledge that is often passed orally from generation to generation, but are also operating in changing circumstances. What is being called for here is a search for openness to enable mutual collaboration that helps to improve both systems.

\section{AUTHOR CONTRIBUTIONS}

The author confirms being the sole contributor of this work and approved it for publication.

\section{FUNDING}

The case studies in the article were generated within the Sida/ SAREC supported study entitled: "Prevention of HIV/AIDS among youth in Kenya through understanding sexuality and reproduction." The study was based at the Department of Community Health, Nairobi University between 1992 and 1996.

Appiah-Kubi, K. (1981). Man Cures, God Heals: Religion and Medical Practice among the Akans of Ghana. New York: Friendship Press.

Beidelman, T. O. (1982). Colonial Evangelism: A Socio-Historical Study of an East African Mission at the Grassroots. Bloomington: Indiana University Press.

Chatora, R. (2003). Migration of Health Professionals. Presentation at 38th Regional Health Ministers' Conference (17-21 November). Livingstone, Zambia.

Chinsembu, K. C. (2009). Model and experiences of initiating collaboration with traditional healers in validation of ethnomedicines for HIV/AIDS in Namibia. J. Ethnobiol. Ethnomed. 5, 1-13. doi:10.1186/1746-4269-5-30

Coe, R. M. (1970). Sociology of Medicine. New York: MacGraw Hill.

Dodge, R. E. (1964). The Unpopular Missionary. Westwood, NJ: Fleming H. Revell Company.

Egger, G. (2012). In search of a germ theory equivalent for chronic disease. Prev. Chronic Dis. 9, 110301. doi:10.5888/pcd9.110301 
Federici, S. (2010). Women, witch-hunting and enclosures in Africa today. Sozial Greschichte Online 3, 10-27.

Foxcroft, G. (2014). Hunting witches. World Policy J. 31, 90-98. doi:10.1177/ 0740277514529721

Gaba, C. R. (1997). Sin and its removal in African traditional religion. Ghana Bull. Theol. 14:275-287. doi:10.1093/jaarel/XLIV.2.275

Galabuzi, C., Agea, J. G., Fungo, B. L., and Namoga, R. M. N. (2010). Traditional medicine as an alternative form of health care system: a preliminary case study of Nangabo Sub-County, Centra Uganda. Afr. J. Tradit. Complement. Altern. Med. 7, 11-16.

Good, C. M., and Kimani, V. N. (1980). Urban traditional medicine: a Nairobi case study. East Afr. Med. J. 57, 301-316.

Groves, C. P. (1948). The Planting of Christianity in Africa. I-IV. London: Lutterworth.

Hauge, H. (1974). Luo Religion and Folklore. Oslo: Universitetsforlaget.

Hoff, W. (1992). Traditional healers and community health. World Health Forum 13, 182-187.

Homsky, J., King, R., Tenywa, J., Kyeyune, P., Opio, A., and Baldad, D. (2004). Defining minimum standards of practice for incorporating African traditional medicine into HIV/AIDS prevention, care, and support: a regional initiative in Eastern and Southern Africa. J. Altern. Complement. Med. 10, 905-910. doi:10.1089/1075553042476731

Ifeanyi, V. (1992). The traditional understanding of health, sickness and care in Nigeria. Dolentium Hominum No. 21-Seventh Year. J. Pontifical Counc. Pastoral Assist. Health Care Work. 3, 30-37.

Kale, R. (1995). Traditional healers in South Africa: a parallel health care system. BMJ 310, 1082-1085. doi:10.1136/bmj.310.6988.1182

Kavelin, C. (2008). Universities as the gatekeeper of the intellectual property of indigenous people's medical knowledge. Aust. J. Indig. Educ. 37, 34-45. doi:10.1375/S1326011100000351

Kenyatta, J. (1938). Facing Mount Kenya. London: Secker Warburg.

Kinoti, H. A. (1983). Aspects of Gikuyu Traditional Morality. Ph.D Thesis, Nairobi University, Nairobi.

Kigen, G. K., Rono, H. K., Kipkore, W. K., and Rotich, J. K. (2013). Current trends of Traditional Herbal Medicine Practice in Kenya: a review. Afr. J. Pharmacol. Ther. 2, 32-37.

Kleinman, A., and van der Geest, S. (2009). 'Care' in health care: remaking the moral world of medicine. Med. Antropol. 21, 159-168.

Kofi-Tsekpo, M. (2004). Institutionalization of African traditional medicine in health care systems in Africa. Afr. J. Health Sci. 11, i-ii.

Labhardt, N. D., Aboa, S. M., Manga, E., Bensing, J. M., and Langewitz, W. (2010). Bridging the gap: how traditional healers interact with their patients. A comparative study in Cameroon. Trop. Med. Int. Health 15, 1099-1108. doi:10.1111/j.1365-3156.2010.02575.x

Last, M., and Chavunduka, G. L. (eds) (1986). “The professionalization of African medicine," in International African Seminars, New Series No. 1 (Manchester: Manchester University Press).

Masanja, M. M. (2015). Albino's plight: will legal methods be powerful enough to eradicate albino's scourge? Int. J. Educ. Res. 3, 231-244.

Mbiti, J. S. (1969). African Religions and Philosophy. Garden City, NY: Anchor Books.

Mildnevora, K. (2016). The modern forms of witchcraft in Zambia: an analysis of local witchcraft narratives in urban settings in Lusaka. Religio revue pro religionistiku 24, 19-51.

Muhibili University of Health and Allied Sciences (MUHAS). (2016). Institute of Traditional Medicine. Available at: http://www.muhas.ac.tz/index.php/ academics/muhas-institutes/110-itm

Mokaila, A. (2001). Traditional Vs. Western Medicine-African Context. Springfield, MO: Drury University. Available at: https://web.archive.org/ web/20060914164630/http://www.drury.edu/multinl/story.cfm?ID= 2524\&NLID $=166$

Moore, H. L., and Sanders, T. (eds) (2001). Magical Interpretations, Material Reality Modernity, Witchcraft and the Occult in Postcolonial Africa. London: Routledge, 253.

Mugambi, J. N. K. (1989). African Heritage and Contemporary Christianity. Kenya: Longman.
Mbembe, A. K. (1992). Provisional notes on the postcolony. J. Int. Afr. Inst. 62, 3-37.

Ness, R. C. (1980). The impact of indigenous healing activity: an empirical study of two fundamentalist churches. Soc. Sci. Med. 14B, 167-180.

Non-hlanhla, N., Olufunke, A., Bronwyn, H., Matthew, C., and Jane, G. (2011). Utilization of traditional healers in South Africa and costs to patients: findings from a national household survey. J. Public Health Policy 32, 124-136. doi:10.1057/jphp.2011.26

Ogden, J., Esim, S., and Grown, C. (2006). Expanding the care continuum for HIV/ AIDS: bringing carers into focus. Health Policy Plan. 21, 333-342. doi:10.1093/ heapol/czl025

Oyebola, D. D. O. (1980). Traditional medicine and its practitioners among the Yoruba of Nigeria: a classification. Soc. Sci. Med. 14A, 23-29.

Rademeyer, J. (2013). "Do $80 \%$ of S. Africans regularly consult traditional healers?," in Africa Check. Available at: https://africacheck.org/reports/do-80-ofsouth-africans-regularly-consult-traditional-healers-the-claim-is-false/

Ray, B. G. (1976). African Religious Symbols, and Community. Michigan: Princeton-Hall.

Ritcher, M. (2003). "Traditional medicines and traditional healers in South Africa," in Discussion Paper. Available at: http://www.tac.org.za/Documents/ ResearchPapers/Traditional_Medicine_briefing.pdf

Simmons, D. (2000). African witchcraft at the millennium: musings on modern phenomenon in Zimbabwe. J. Int. Inst. 7, 1-6.

Stenberg, S. H. (2010). Modernity through the eyes of witchcraft: a radical critique of categorisation. Global Discourse 1, 53-61. doi:10.1080/23269995.2010. 10707838

Taye, O. R. (2009). Yoruba traditional medicine and the challenge of integration. J. Pan Afr. Stud. 3, 79-90.

Tilley, H. (2015). Medicine, empires and ethics in colonial Africa. AMA J. Ethics $18,743-753$.

Timmermans, K. (2003). Intellectual property rights and traditional medicine: policy dilemmas at the interface. Soc. Sci. Med. 57, 745-756. doi:10.1016/ S0277-9536(02)00425-2

Ukpabio, H. (2011). Pray Your Self to Freedom, 140 Stormy Prayers Against Witchcraft Forces. Calabar: Kings View Publication House.

UNICEF. (2010). Children Accused of Witchcraft: An Anthropological Study of Contemporary Practices in Africa. Dakar: WCARO.

WHO. (1978). Primary Health Care: Report of the International Conference on Primary Health Care, Alma-Ata, USSR, 6-12 September, Geneva.

WHO. (2008). Fact Sheet on Traditional Medicine (TM). WHO. Available at: http://www.siav-itvas.org/images/stories/doc/agopuntura_scientifica/ WHO_Traditional_medicine_2008.pdf

WHO. (2011). Progress Report on Decade of Traditional Medicine in the African Region. Yamoussoukro: Regional Committee For Africa, AFR/RC61/PR/2.

Wilson, M. (1957). Rituals of Kinship among the Nyakyusa. New York: Oxford University Press.

Wreford, J. (2005). “'We can help!” A literature review of current practice involving traditional African healers in biomedical HIV/AIDS interventions in South Africa," in CSSR Working Paper No. 108 (Cape Town: University of Cape Town).

Yach, D., Hawkes, C., Gould, C. L., and Haman, K. J. (2004). The global burden of chronic diseases: overcoming impediments to prevention and control. JAMA 291, 2616-2622. doi:10.1001/jama.291.21.2616

Zahan, D. (1979). The Religion, Spirituality, and Thought of Traditional Africa. Chicago: The University of Chicago Press.

Conflict of Interest Statement: The author declares that the research was conducted in the absence of any commercial or financial relationships that could be construed as a potential conflict of interest.

Copyright (c) 2017 Ahlberg. This is an open-access article distributed under the terms of the Creative Commons Attribution License (CC BY). The use, distribution or reproduction in other forums is permitted, provided the original author(s) or licensor are credited and that the original publication in this journal is cited, in accordance with accepted academic practice. No use, distribution or reproduction is permitted which does not comply with these terms. 